\title{
Cationic Microemulsion Polymerization of Alkyl Acrylates
}

\author{
Issa Katime $^{1}$, Jesús Arellano ${ }^{2}$, Eduardo Mendizábal $^{3}$, Jorge Flores ${ }^{3}$ \\ ${ }^{1}$ Grupo de Nuevos Materiales y Espectroscopia Supramolecular, Facultad de Ciencia y Tecnología, Bilbao, España; ${ }^{2}$ Departamento \\ de Ingeniería Química, Universidad de Guadalajara, Guadalajara, Jalisco, México; ${ }^{3}$ Departamento de Química, Universidad de \\ Guadalajara, Guadalajara, Jalisco, México. \\ Email: issa.katime@ehu.es
}

Received September $13^{\text {th }}, 2010$; revised October $26^{\text {th }}, 2010$; accepted October $30^{\text {th }}, 2010$.

\begin{abstract}
Here we present the polymerization of $n$-butyl acrylate (BA), ethyl acrylate (EA) and methyl acrylate (MA) in tri-component microemulsions, using a cationic surfactant such as dodecyl trimetyl ammonium bromide in water, as a function of temperature, initiator type and, monomer and initiator concentration. The final latexes are transparent and blue color, with particle size ranging between 20 and $60 \mathrm{~nm}$ determined by quasielastic light scattering $(Q L D)$ and SEC molar masses of the order of $10^{6} \mathrm{~g} / \mathrm{mol}$. Reaction times are short and reaction rates are high with final conversions between 70 and $98 \%$ depending on the monomer and the reaction conditions.
\end{abstract}

Keywords: Microemulsion Polymerization, Particle Size, Nanoparticles, Quasielastic Light Scattering, Surfactant

\section{Introduction}

Microemulsion polymerization was born as an alternative process for the production of polymeric latexes with unique particle size, molar masses and structure. Synthesis of stable latexes with particle size ranging from 10 a $35 \mathrm{~nm}$ has been possible through this process where a fast polymerization affords high molar mass polymers $[1,2]$. Stoffer and Bone [3,4] first reported microemulsion polymerization in 1980. Most microemulsion polymerization reported in the 80 's, were carried out in four and five component systems [2]. The first three component microemulsion polymerization (water, surfactant and monomer) was reported by Pérez-Luna et al. in 1990 $[5,6]$. Since then microemulsion polymerization of different monomers in three component systems have been reported [7-18], where the influence of different parameters on the polymerization kinetics and on the obtained latexes have been studied [12,13,19-27]. Some of the parameters are: 1) Initial monomer concentration in the system, polymerization rate and conversion increase with initial monomer concentration due to the higher number and size of the drops being formed in the microemulsion. Gan et al. [12] and Pérez-Luna et al. [6] report similar behavior of the polymerization reaction rates for styrene in three and four components, 2) Temperature, reaction rates are higher when temperature is raised due to a quick increase in the initiator decomposition rate. Final conversion increases as the mobility of the macromolecules increases with temperature. Guo et al. [19] and Rodríguez-Guadarrama $[10,11]$ report activation energy values for microemulsion polymerization of methyl methacrylate and, 3) The initiator and the surfactant, the rate of polymerization and the rate of conversion increase with initiator concentration. To understand the influence of the type of initiator and surfactant the structure of them has to be considered. Guo et al. [19] studied the polymerization of styrene in SDS and pentanol and reported higher reaction and conversion rates; with an initiator soluble in the aqueous phase KPS, than those obtained in the oil phase AMBN. Gan et al. [13] study styrene polymerizations with SDS or CTAB using different initiators. They observed a higher reaction rate with SDS than with CTAB. Similar results were observed for other systems attributed to the "electrostatic charge effect" and to a chain transfer reaction between the bromide ion of the surfactant and the KPS free radical [23], 4) electrolyte addition, this effect depends on factors such as structure and concentration of the electrolyte; addition of the electrolyte greatly alters one phase region of these systems decreasing the solubility between water and surfactants. Full et al. [23], studied the addition of $\mathrm{KBr}$ on KPS initiated styrene microemulsion polymerization in 
microemulsion with dodecyl trimetyl ammonium bromide, finding that reaction rate decreases, as well as particle size and molar masses as salt concentration increases. Similar results were obtained when $\mathrm{NaBr}$ was used as electrolyte in styrene microemulsion polymerization [22,23] and, 5) alcohol addition, alcohols drastically modify the one phase region of water-oil-surfactant, as shown by Gan et al. [12] and Puig et al. [20]. Gan et al. [13], reported higher molar masses for more amphifilic surfactants. Puig et al. [20], report that reaction rate, conversion degree and molar mass decrease with alcohol content. They also found influence of the cosurfactant.

In this work we present the polymerization of n-butyl acrylate (BA), ethyl acrylate (EA) and methyl acrylate (MA) in tricomponent microemulsions, using a cationic surfactant such as dodecyl trimetyl ammonium bromide in water as a function of temperature, monomer and initiator concentration and initiator type. Particle size and molar mass of the final latexes are of the order of 20 and $60 \mathrm{~nm}$ and $106 \mathrm{~g} / \mathrm{mol}$, respectively. High reaction rates and conversions above $70 \%$ were found in all cases. Final latexes were transparent and slightly blue.

\section{Experimental}

Materials. Aldrich 99\% pure dodecyl trimethyl ammonium bromide (DTAB) was used as surfactant. WAKO 2,2'-azobis(amidinopropane) V-50, Fluka potassium persulfate KPS, and Merck 2,2-Azobisisobutyronitrile (AIBN), all more than $99 \%$ pure, were used as initiators. Acrylates such as ethyl (EA), methyl (MA) and n-butyl (n-BA) from Scientific Polymer Products 99\% were used, after passing them through a DE-HIBIT 100 Scientific Polymer Products column to remove the inhibitor. Merck 99\% hydroquinone was used to inhibit the reaction. Water was distilled twice. Chromatographic grade Merck tetrahydrofurane (THF) was used as mobile phase in molar mass SEC determinations.

Phase Diagram Determination. A weighed sample of the monomer aqueous solution ( $50 \mathrm{wt} \%$ ) was placed in a $25-\mathrm{mL}$ vial and thermostated at $25^{\circ} \mathrm{C}$. Then, the oil phase was slowly added, drop by drop, under vigorous stirring until the turbid emulsion turned into an optically transparent microemulsion. The final composition of the microemulsion was determined via weighing. The conductivity of the microemulsion showed that had a globular structure, which was formed by micelles swollen with the aqueous phase. The systems studied in this article were stable for a period of at least several hours.

Synthesis and Kinetic Studies. Kinetics were followed by dilatometry, polymerizations were carried out in a small two mouth reactor (approximately $30 \mathrm{~mL}$ ), with a capillary tube connected to one of them $(40 \mathrm{~cm}$ high and
$0.1 \mathrm{~cm}$ diameter) and a small septum to the other one to inject the initiator. An adequately prepared microemulsion is added to the reactor, placed in a constant temperature bath with continuous stirring, under argon stream for 45 minutes and them left until it reaches the desired temperature. As the system increases its volume due to thermal expansion, thermal equilibrium is thought to be reached when the meniscus reaches a constant height in the capillary. At this moment the solution of the initiator is injected and timing of the reaction is started by observing the decrease in the capillary height assuming that volume change is proportional to conversion. The dilatometer is calibrated calculating the conversion degree by gravimetry of the final latexes in each reaction.

Particle Size. Particle size was determined using a quasielastic light scattering (QLS) AMTEC apparatus equiped with a He-Ne laser, 632.8 wavelength and $60 \mathrm{~mW}$ power. The instrument has a BI-9000AT correlator. Correlation data are analyzed by the cumulant method which supplies an average $\mathrm{r}=\mathrm{q} 2$, where $\mathrm{q}$ is the dispersion vector and D the diffusion coefficient. Diffusion coefficient measurements are presented in terms of apparent radius according to Stokes law and assuming that the viscosity of the solvent is that of pure water. Molar masses were calculated with a SEC instrument equipped with a Knauer HPLC64 injection pump, a Rheodyne 7125 manual injector, a Knauer differential refractive index detector, two Polymer Laboratories PLGEL mixed-C columns, a Polymer Laboratories PL-LALS interphase, and a PC-486 microcomputer with PL Caliber SEC Software. Merck chromatographic grade tetrahydrofurane (THF) was used as mobile phase.

\section{Results and Discussion}

Polymerization of n-butyl acrylate (n-BA) and ethyl acrylate (EA) in three component microemulsions prepared with dodecyl trimethyl ammonium bromide and water are faster than those of methyl acrylate (MA) in the same type of micro emulsions. Reaction times are similar to those observed for these monomers in four component microemulsions [28-30].

Reactions were carried out using a constant ratio of dodecyl trimethyl ammonium bromide/water 15/85, and varying different parameters in order to find out how each one influenced the polymerization kinetics especially the initiation step. Polymer densities used to calculate conversions are $1.22 \mathrm{~g} / \mathrm{mL}$, for poly(methyl acrylate), $1.12 \mathrm{~g} / \mathrm{mL}$, for poly(ethyl acrylate) and $1.09 \mathrm{~g} / \mathrm{mL}$, for de n-butyl acrylate [31].

Temperature effect. To study the temperature effect on these polymerizations, in cationic microemulsions prepared in DTAB and water, a $4 \%$ monomer composition and $14.4 \%$ DTAB and $81.6 \%$ water were chosen. The 
reaction was initiated with $0.5 \% \mathrm{~V}-50$ with respect to the monomer and the different temperature were 50, 55, 60 and $65^{\circ} \mathrm{C}$.

Monomer to polymer conversion plots as a function of time, and polymerization rate as a function of conversion for the three monomers show the same general trend at the chosen temperatures. Figures $\mathbf{1}$ and $\mathbf{2}$ show the results obtained for the polymerization of n-butyl acrylate. As can be seen, the polymerizations are fast and reach degrees of conversion higher than $90 \%$ for n-butyl acrylate, between 85 and $88 \%$ for ethyl acrylate at the chosen temperatures, and higher than $70 \%$ for methyl acrylate during 100 minutes at 60 and $65^{\circ} \mathrm{C}$ ).

Initial reaction rate gets smaller as reaction temperature is decreased, however, at the end, similar conversion degrees are reached in the different reactions with respect

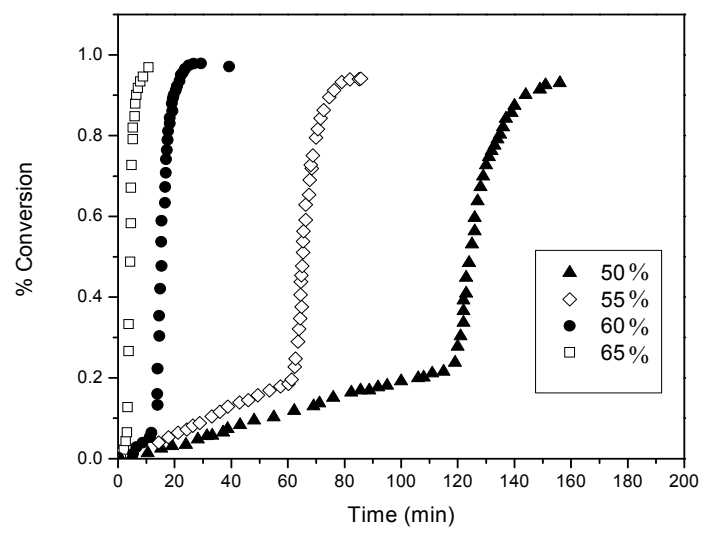

Figure 1. Conversion as a function of time for a polymerization initiated with $\mathrm{V}-50 \mathrm{0.5} \%$ (with respect to the monomer) at different temperatures in micro emulsions containing $4 \%$ of n-butyl acrylate, $14.4 \%$ DTAB and $81.6 \%$ water.

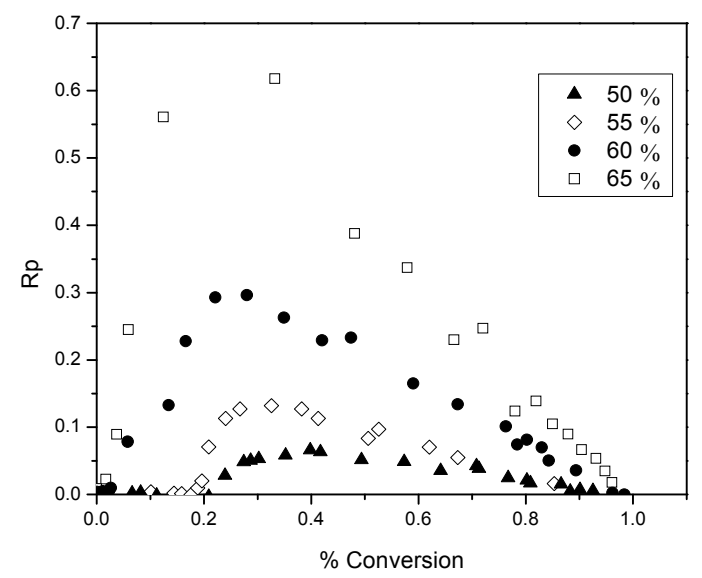

Figure 2. Reaction rate variation as a function of degree of conversion for polymerizations initiated with $0.5 \% \quad \mathrm{~V}-50$ (with respect to the monomer) at different temperatures in micro emulsions containing $4 \%$ n-buyl acrylate, $14.4 \%$ DTAB and $81.6 \%$ water. to each monomer. The latexes look transparent at the beginning but become cloudy as the reaction proceeds. It can be observed that the reaction rate only show two intervals typical of micro emulsion polymerization, more clearly in the case of n-butyl and ethyl acrylates than in methyl acrylate, due to the smaller water solubility of the first two. Solubilities of methyl, ethyl and n-butyl acrylates are 4.76, 1.48 and $0.2 \%$, respectively [32]. Polymerization rates increase with reaction temperature. This behaviour is due to the increase of free radical flow as the initiator decomposition rate and the propagation constant increase significantly with temperature $[12,19]$.

Maximum polymerization rate depends on temperature similar to Arrhenius prediction. Activation energy obtained from the kinetic data is $132.6 \mathrm{~kJ} / \mathrm{mol}$ for n-butyl acrylate and 128.2 and $139.6 \mathrm{~kJ} / \mathrm{mol}$ for ethyl and methyl acrylate, respectively. These figures are higher than those reported for different alkyl acrylates polymerized in a similar manner $[10,14]$.

In Figure 3, monomer to polymer conversion as a function of reaction time for methyl, ethyl, and n-butyl acrylates at 50 and $60^{\circ} \mathrm{C}$ are compared. N-butyl acrylate polymerizations are faster than those of ethyl acrylate and these ones faster than methyl acrylate at both temperatures; they get faster as the substituent size increases. An increase in the polymerization rate is observed as the monomer water solubility decreases. It is also remarkable that the conversion graphs change from a typical micro emulsion polymerization to a solution polymerization behaviour as the monomer water solubility increases.

In Figure 4, polymerization rate variations as a function of conversion for the different monomers at 50 and $60^{\circ} \mathrm{C}$ are shown. Two typical micro emulsion polymerization intervals are observed for n-butyl acrylate more

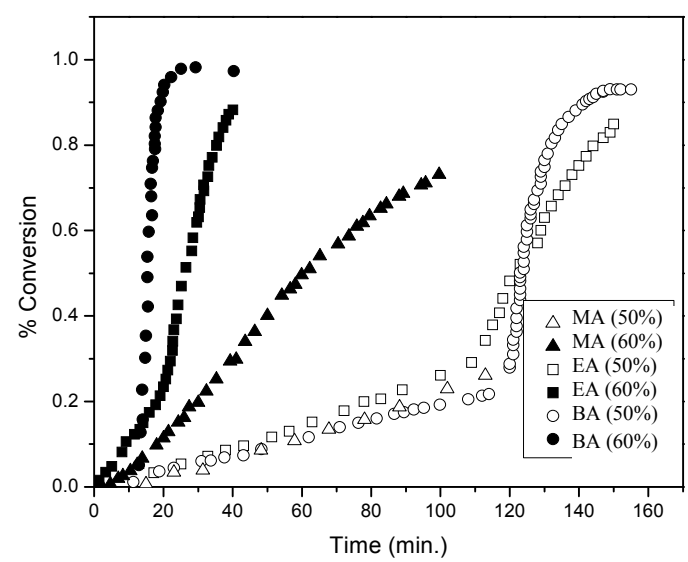

Figure 3. Conversion as a function of time for a polymerization initiated with $\mathrm{V}-50 \mathrm{0.5} \%$ (with respect to the monomer) at 50 and $60^{\circ} \mathrm{C}$ in micro emulsions containing $4 \%$ of monomer, $\mathbf{1 4 . 4 \%}$ DTAB and $\mathbf{8 1 . 6 \%}$ water for methyl, ethyl and n-butyl acrylates. 


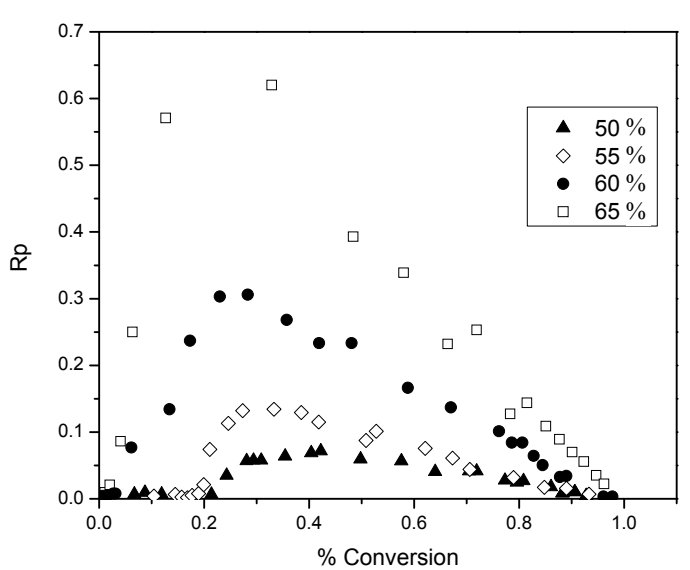

Figure 4. Reaction rates as a function of conversion for a polymerization initiated with $0.5 \% \mathrm{~V}-50$ (with respect to the monomer) at 50 and $60^{\circ} \mathrm{C}$ in micro emulsions containing $4 \%$ of monomer, $14.4 \%$ DTAB and $81.6 \%$ water for methyl, ethyl and n-butyl acrylates.

clearly than in the case of ethyl and methyl acrylates. This behaviour is less clear for the last one due to its higher water solubility. It is apparent that the reaction rate decreases as the monomer water solubility increases. Bearing in mind that initiation probability is directly proportional to micelle concentration, as they contain the monomer inside them (micellar nucleation), it is clear that the more water soluble is the monomer and, as a consequence the initiation step is more favorable, the higher is the polymerization rate.

Table 1 shows that for the three monomers, particle size and maximum polymerization rate increase with temperature. Molar masses are of the order of $106 \mathrm{~g} / \mathrm{mol}$. With respect to particle size, as the temperature increases, so does the monomer diffusion rate which implies a larger amount of monomer per particle hence a larger size. The maximum polymerization rate increases as the po-

Table 1. Particle size, $D_{\mathrm{p}}$, Maximum polymerization rate, $V_{\text {pmax }}$, mass average molar mass, $M_{w}$, of final latexes as a function of temperature for polymerizations initiated with $0.5 \% \mathrm{~V}-50$ (with respect to the monomer) in micro emulsions containing $4 \%$ n-butyl acrylate, $14.4 \%$ DTAB and $\mathbf{8 1 . 6 \%}$ water.

\begin{tabular}{|c|c|c|c|}
\hline Temperature $(\mathrm{C})$ & $\mathrm{D}_{\mathrm{p}}(\mathrm{nm})$ & $\mathrm{V}_{\mathrm{pmax}}$ & $\mathrm{M}_{w} \times 10^{6} \mathrm{~g} / \mathrm{mol}$ \\
\hline \multicolumn{4}{|c|}{ n-butyl acrylate } \\
\hline 50 & 23 & 0.068 & - \\
\hline 60 & 26 & 0.296 & 1.12 \\
\hline \multicolumn{4}{|c|}{ Ethyl acrylate } \\
\hline 50 & 30.5 & 0.018 & - \\
\hline 60 & 32 & 0.060 & 0.948 \\
\hline \multicolumn{4}{|c|}{ Methyl acrylate } \\
\hline 50 & 42 & 0.003 & - \\
\hline 60 & 53 & 0.011 & 1.05 \\
\hline
\end{tabular}

lymerization rate increases with a higher radical flow because of a higher initiator decomposition rate with temperature.

Monomer concentration effect. In order to study the effect of monomer concentration in the polymerization of n-butyl, ethyl and methyl acrylates, in DTAB cationic microemulsions $1,2,3$, and $4 \%$ monomer and a constant surfactant/water ratio were used. A fixed 15/85 $\mathrm{DTAB} /$ water ratio was polymerized. Reactions were carried out at $60^{\circ} \mathrm{C}$, initiated with $0.02 \% \mathrm{~V}-50$ with respect to the total weight (initiator concentration was calculated with respect to the initial monomer concentration where this was $4 \%$. This value was kept constant for the rest of the reactions).

Monomer to polymer conversion with time plots, polymerization rates with respect to conversion, for the three monomers show the same trend. Figures 5 and $\mathbf{6}$

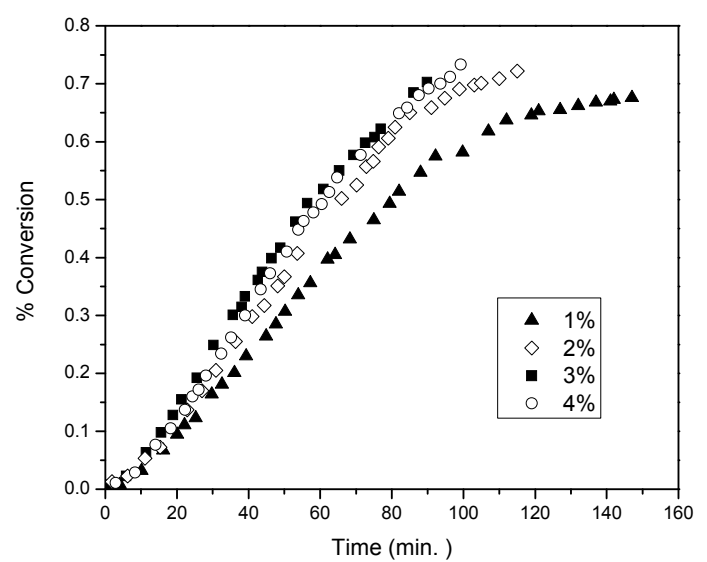

Figure 5. Monomer conversion with time for the polymerization of different methyl acrylate concentrations initiated with $0.02 \% \mathrm{~V}-50$ in $15 / 85 \mathrm{DTAB} /$ water microemulsions at $60^{\circ} \mathrm{C}$.

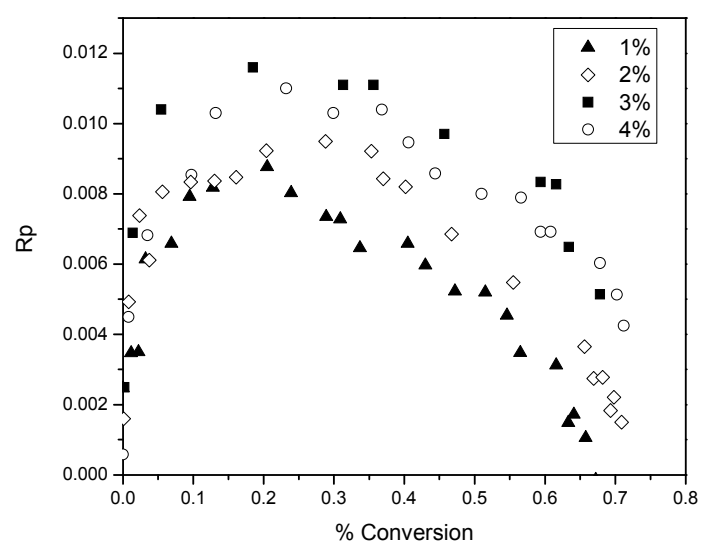

Figure 6. Reaction rates with conversion for the polymerization of different methyl acrylate concentrations initiated with $0.02 \% \mathrm{~V}-50$ in 15/85 DTAB/water micro emulsions at $60^{\circ} \mathrm{C}$. 
show monomer to polymer conversion plots with time and polymerization rates with respect to conversion for methyl acrylate at the same initial monomer different concentrations. Conversion degrees for methyl acrylate oscillate between 70 and $75 \%$ for the different monomer concentrations; for ethyl acrylate around $85 \%$ except for $1 \%$ monomer concentration where it reaches $70 \%$. On the other hand final conversions for n-butyl acrylate are all higher than $94 \%$. In the conversion plots for the three acrylates a monomer concentration effect is not observed (see Figure 5 for methyl acrylate), except for 1\% monomer concentration. In general, latexes for the three monomers are transparent at the beginning of the reaction, except for a slightly blue color for higher initial monomer concentrations. At the end of the reaction they look cloudy with cloudiness increasing with monomer concentration. Two intervals typical of microemulsion polymerization are observed for the polymerization rate in al cases (Figure 6 for butyl acrylate).

Figure 7 shows monomer to polymer conversion plots as a function of reaction time for methyl, ethyl and n-butyl acrylates at 2 and 4 weight percent with respect to total weight. Acrylate polymerization rates follow this order: n-butyl > ethyl > methyl. Polymerizations are faster and an increase in polymerization rate with monomer water solubility is observed.

Figure 8 shows polymerization rates with respect to conversion for the above monomers at 2 and 4 monomer weight percent with respect to total weight. Two intervals typical of microemulsion polymerization are observed although this behaviour is less clear as the monomer becomes less water soluble. It is clear how reaction rate decreases as monomer water solubility increases.

Dependence of polymerization rate on monomer concentration has been reported for most microemulsion

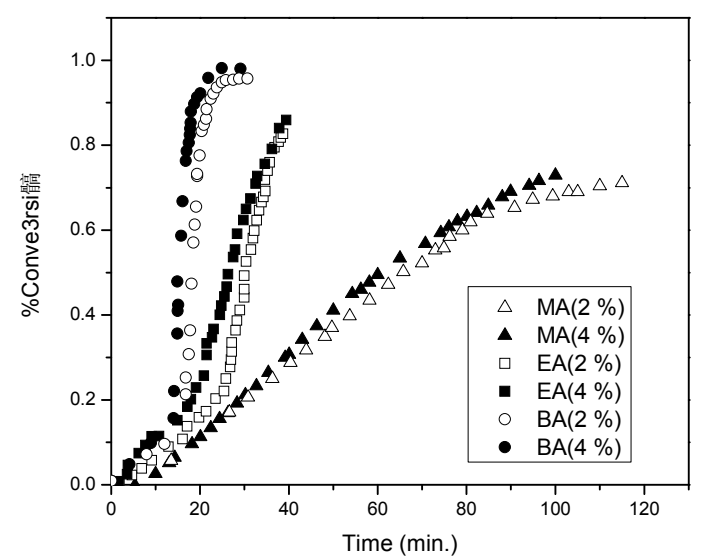

Figure 7. Conversion with time for the polymerization of methyl, ethyl and n-butyl acrylates initiated with $0.02 \%$ $\mathrm{V}-50$ in 15/85 DTAB/water micro emulsions with 2 and $4 \%$ monomer concentration at $60^{\circ} \mathrm{C}$.

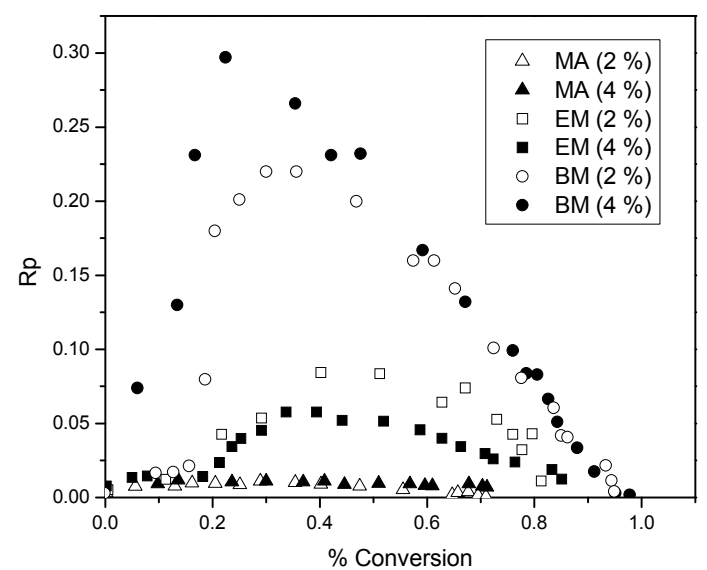

Figure 8. Reaction rates with conversion for the polymerization of different methyl acrylate concentrations initiated with $0.02 \% \mathrm{~V}-50$ in $15 / 85 \mathrm{DTAB} /$ water micro emulsions with 2 and $4 \%$ monomer concentration at $60^{\circ} \mathrm{C}$.

polymerizations as opposed to what is observed in emulsion $[6,12,13]$. In emulsion polymerizations the majority of the monomer is dispersed as drops which do not significantly participate in the initiation step as this takes place in the micelles. It is well known that in microemulsion polymerization most of the monomer is located in the swollen micelles and the rest is dissolved in water. Therefore, a competition for radical capture takes place between the monomer dissolved in water (homogeneous nucleation) and the one in the micelles (micellar nucleation). This big increase in active sites, where the reaction can be initiated, produces an increase in the initiation step rate, the one controlling the reaction rate. In our case an important effect of monomer concentration has not been observed for the three acrylates at the concentrations we used (smaller than those used by other authors) which suggests a proportional variation in the interfacial ratio: swollen micelles/water phase, at low monomer concentration; this favors homogeneous nucleation and polymerization rates do not show big change, this is our case, which has also been reported for n-hexyl methacrylate [33]. Concluding, it is micellar nucleation which has the highest impact on reaction rate increase and when homogeneous nucleation is favored reaction rate tends to decrease. When comparing different acrylates polymerization rates a decrease in final conversions and polymerization rates, when monomer water solubility increases, is observed. In other words, by increasing the relative amount of monomer in the aqueous phase, which favors homogeneous nucleation, polymerization rate is decreased. In general, when micellar nucleation in a microemulsion polymerization is favored, reaction rate increases, and when homogeneous nucleation is favors, polymerization rate decreases. 
Table 2 shows how particle size increases with initial monomer concentration and maximum polymerization rate does not show a clear trend, for the three monomers under study. Molar masses are of the order of $106 \mathrm{~g} / \mathrm{mol}$. With respect to particle size, while for n-butyl acrylate no change is observed, a size change is apparent for the other two monomers as the initial monomer concentration is increased, which can be interpreted as a beginning in particle coagulation due to the nature of the monomers and to the similarity in the kinetics of their polymerizations. Maximum polymerization rate is very similar, no change in reaction order is observed for the three cases.

Effect of initiator (V-50) concentration. To study the effect of initiator (V-50) concentration on n-butyl, ethyl and methyl acrylates microemulsion cationic polymerizations in DTAB/water, the following composition was used: $4 \%$ monomer, $14.4 \%$ DTAB and $81.6 \%$ water. Reactions were carried out at $60^{\circ} \mathrm{C}, \mathrm{V}-50$ concentrations were $0.25,0.50,0.75$ and $1.00 \%$. Initiator concentration is given as weight \% with respect to initial monomer concentration. V-50 is a water soluble initiator which decomposes to give two cationic free radicals. Monomer to polymer conversion vs. time plots and those for polymerization rates Vs conversion for the three monomers, show similar trends at the different initiator concentrations employed. Figures $\mathbf{9}$ and $\mathbf{1 0}$ show monomer to polymer conversion vs. time plots and polymerization rates vs. conversion for ethyl acrylate at different V-50 concentrations.

This polymerization reach conversions between 86 and $93 \%$ for ethyl acrylate depending on initiator concentration, while for n-butyl acrylate, conversions higher than $95 \%$ are reached in all cases. On the other hand, for methyl acrylate conversions are between 70 and $75 \%$. In general latexes look similar to those already described; transparent at the beginning of the reaction they become

Table 2. Particle size, $D_{p}$, maximum polymerization rate, $V_{\text {pmax }}$, mass average molar mass, $M_{w}$, for final latexes as a function of initial monomer concentration, $\mathrm{C}_{\mathrm{m}}$, for $\mathbf{0 . 0 2 \%}$ $\mathrm{V}-50$ initiated polymerizations in microemulsions with a 15/85 DTAB/water ratio.

\begin{tabular}{cccc}
\hline $\mathrm{C}_{\mathrm{m}}$ & $\mathrm{D}_{\mathrm{p}}(\mathrm{nm})$ & $\mathrm{V}_{\mathrm{pmax}}$ & $\begin{array}{c}\mathrm{M}_{\mathrm{w}} \times 10^{6} \\
\mathrm{~g} / \mathrm{mol}\end{array}$ \\
\hline \multicolumn{4}{c}{$\mathrm{n}$-butyl acrylate } \\
4 & 24.7 & 0.230 & - \\
4 & 26 & 0.296 & 1.12 \\
2 & \multicolumn{4}{c}{ Ethyl acrylate } \\
4 & 20 & 0.075 & - \\
& 32 & 0.060 & 0.948 \\
4 & \multicolumn{4}{c}{ Methyl acrylate } \\
\hline
\end{tabular}

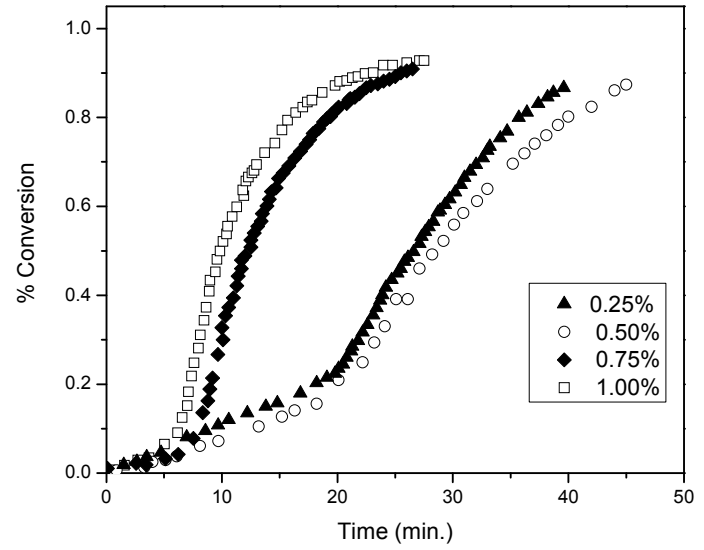

Figure 9. Polymer conversion (\%) vs. time for polymerizations initiated with different concentrations of V-50 (with respect to monomer) in microemulsions containing $4 \%$ ethyl acrylate, $14.4 \%$ DTAB and $81.6 \%$ water, carried out at $60^{\circ} \mathrm{C}$.

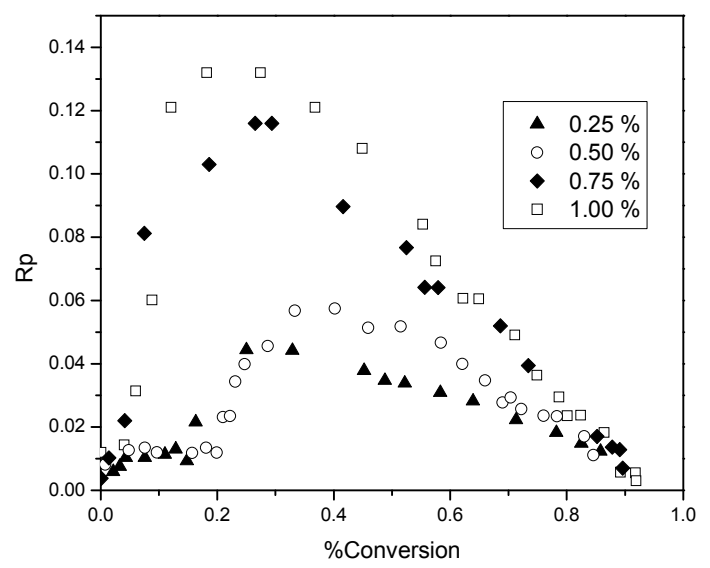

Figure 10. Reaction rates vs. conversion for polymerizations initiated with different concentrations of $\mathrm{V}-50$ (with respect to monomer) in microemulsions containing $4 \%$ ethyl acrylate, $14.4 \%$ DTAB and $81.6 \%$ water, carried out at $60^{\circ} \mathrm{C}$.

cloudy with reaction progress. Reaction rate decreases as initiator concentration decreases. Two typical microemulsion polymerization intervals for reaction rate are only observed in the case of less water soluble monomers. Polymerization rate increases as initiator concentration increases. This behavior is due to the increase in free radical flow, as it was mention before, which highly increases the probability of initiation in this reacting system.

In Figure 11, monomer to polymer conversion vs. time is compared for methyl, ethyl and n-butyl acrylates at $\mathrm{V}-50$ concentrations of 0.5 and $1.0 \%$ (with respect to monomer). N-butyl acrylate polymerizations are the fastest followed by those of ethyl acrylate and methyl acrylate (the slowest) Polymerizations are faster and as a consequence an increase in polymerization rate, as 


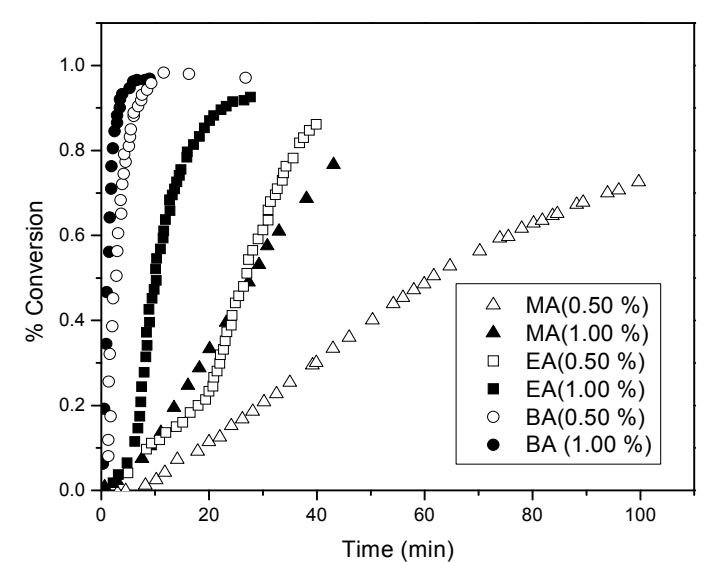

Figure 11. Conversion vs. time for polymerizations initiated with different concentrations of $\mathrm{V}-50$ (with respect to monomer) in microemulsions containing $4 \%$ monomer, $14.4 \%$ DTAB and $81.6 \%$ water, carried out at $60^{\circ} \mathrm{C}$. The monomers were methyl, ethyl and n-butyl acrylates.

monomer water solubility decreases, is observed. Monomer to polymer conversion plots are less pronounced as the monomer becomes more water soluble, until a solution polymerization behavior is reached. In Figure 12, polymerization rate vs. conversion for the three alkyl acrylates are presented. The two microemulsion polymerization typical intervals are observed in these plots (these behavior is more noticeable as monomer water solubility decreases). Once again, a reaction rate decrease as monomer water solubility increases is observed.

A rapid polymerization rate increase is observed as initiator concentration increases, mainly due to free radical flow increase $[11,14,19,33]$, which increases the col lision probability between monomer swollen micelles and the radicals (micellar nucleation). In the same way,

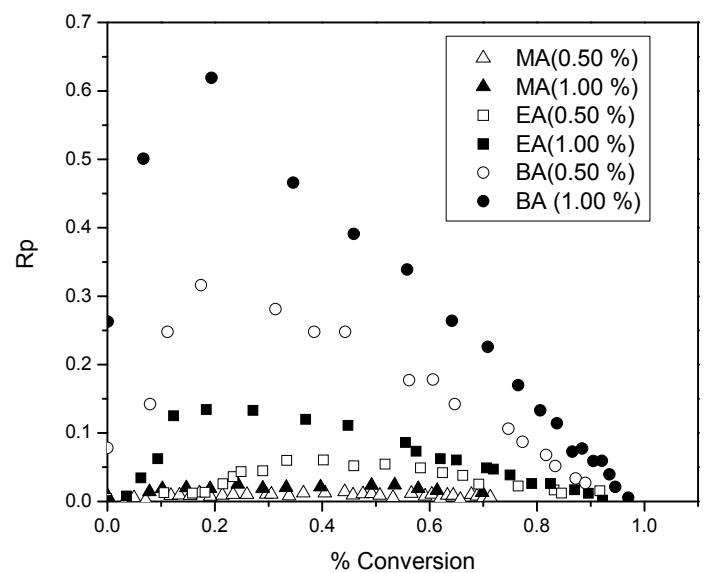

Figure 12. Reaction rates vs. conversion for polymerizations initiated with different concentrations of $\mathrm{V}-50$ (with respect to monomer) in microemulsions containing $4 \%$ monomer, $14.4 \%$ DTAB and $81.6 \%$ water, carried out at $60^{\circ} \mathrm{C}$. The monomers were methyl, ethyl and n-butyl acrylates. the probability of oligomer formation with water soluble monomer, which is then stabilized by surfactant or penetrate in monomer swollen particles to form new particles (homogeneous nucleation), increases. In Table 3, particle size for the three monomers stays constant and maximum polymerization rate increases with initiator concentration, due to an increase in free radical flow.

Initiator type influence. In order to study the influence of the type of initiator, cationic microemulsion polymerizations of methyl, ethyl and n-butyl acrylates in water and dodecyl trimethyl ammonium bromide were carried out. Besides V-50, water soluble potassium persulfate which decomposes in anionic free radicals (as opposed to $\mathrm{V}-50$ which decomposes in cationic free radicals) and 2,2-azobisisobutyronitrile (AIBN), oil soluble initiator, were used under the same conditions: $4 \%$ monomer, $14.4 \%$ DTAB and $81.6 \%$ water, $0.5 \%$ initiator (with respect to monomer) and $60^{\circ} \mathrm{C}$.

Behavior upon variation of initiator type is very similar for ethyl and n-butyl acrylates. Monomer to polymer conversion vs. time plots show that polymerizations initiated with V-50 are faster than those initiated with AIBN, and the latter faster than those with KPS. In Figure 13, monomer to polymer conversion plots for n-butyl acrylate with the three initiators are compared (trends are similar for the three monomers). Final conversions for the three initiators are similar.

In Figure 14, polymerization rates vs. conversion for $\mathrm{n}$ butyl acrylate with the three initiators are compared (the other monomers show similar trends). The two intervals typical of emulsion polymerization are observed for all initiators. Reaction rates are higher for $\mathrm{V}-50$ than for AIBN and for KPS, as the decomposition rates of these initiators follow the same order Decomposition constant for V-50 $3.2 \times 10^{-5} \mathrm{~s}^{-1}$ at $60^{\circ} \mathrm{C}$ [34], AIBN's is $1.25 \times 10^{-5}$ $\mathrm{s}^{-1}$ at $60^{\circ} \mathrm{C}$ [35] and KPS's is $3.1 \times 10^{-6} \mathrm{~s}^{-1}$ at $60^{\circ} \mathrm{C}$ [35], which greatly influences reaction rates. Although, in the

Table 3. Particle size $D_{p}$, maximum polymerization rate, $V_{\text {pmax }}$, mass average molar mass, $M_{w}$, for final latexes as a function of $\mathrm{V}-50$ concentration, $C_{i}$, (with respect to monomer) in microemulsions containing $4 \%$ monomer, $14.4 \%$ DTAB and $81.6 \%$ water, carried out at $60^{\circ} \mathrm{C}$.

\begin{tabular}{cccc}
\hline $\mathrm{C}_{\mathrm{i}}$ & $\mathrm{D}_{\mathrm{p}}(\mathrm{nm})$ & $\mathrm{V}_{\mathrm{pmax}}$ & $\mathrm{M}_{\mathrm{w}} \mathrm{x} 10^{6} \mathrm{~g} / \mathrm{mol}$ \\
\hline \multicolumn{5}{c}{ n-butyl acrylate } \\
0.5 & 26 & 0.296 & 1.12 \\
1.0 & 28 & 0.570 & - \\
\multicolumn{5}{c}{ Acrilato de etilo } \\
0.5 & 32 & 0.060 & 0.948 \\
1.0 & 35 & 0.137 & - \\
\multicolumn{5}{c}{ Acrilato de metilo } \\
0.5 & 53 & 0.011 & 1.05 \\
1.0 & 59 & 0.023 & - \\
\hline
\end{tabular}




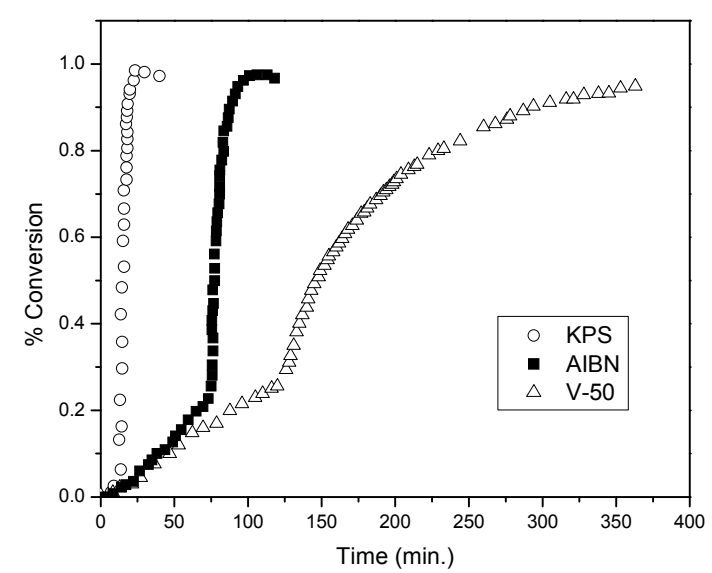

Figure 13. Conversion vs. time for polymerizations initiated with $0.5 \%$ KPS, AIBN and V-50 al (with respect to monomer) in microemulsions containing $4 \%$ n-butyl acrylate, $14.4 \%$ DTAB and $81.6 \%$ water, carried out at $60^{\circ} \mathrm{C}$.

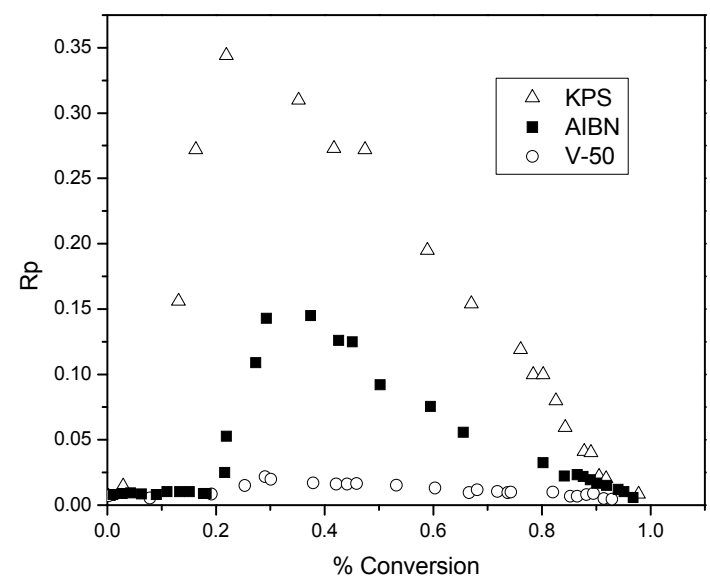

Figure 14. Reaction rate vs. conversion for polymerizations initiated with $0.5 \% \mathrm{KPS}$, AIBN and V-50 (with respect to monomer) in microemulsions containing $4 \%$ n-butyl acrylate, $14.4 \%$ DTAB and $81.6 \%$ water, carried out at $60^{\circ} \mathrm{C}$.

case of water soluble initiators, other factors such as electrostatic interactions between positively charged microemulsion drops and free radicals generated in initiator decomposition should be taken into account.

KPS decomposes in anionic free radicals which interact strongly with cationic microemulsion drops then the free radicals are attracted to the drop surface where they are "trapped", reducing free radical concentration in the aqueous phase hence decreasing the initiator efficiency. This effect is not observed with V-50. This behavior has been detected in styrene [6] and methyl methacrylate [11] microemulsion polymerizations. It is well known that free radicals liberated by KPS, suffer reaction transfer with bromide counter ions present in the surfactant $[23,36]$, which is not the case with V-50. For oil soluble AIBN whose radicals are inside the microemulsions drop, the possibility of self termination is much higher than for water soluble initiators, a major factor which makes initiation more difficult and decreases AIBN initiated overall polymerization rates.

\section{Conclusions}

Monomer solubility has a very strong effect on conversion and reaction rate, as it plays a very important role in the initiation step of microemulsion polymerizations. Polymerization rate increases as monomer water solubility decreases, independent of other factors such as temperature, monomer initial concentration, and initiator type and concentration. As monomer water solubility becomes higher, monomer to polymer conversion graphs change from the typical monomer to polymer conversion curves for microemulsion polymerizations to a typical solution polymerization curve. Final conversion and reaction rates do not show an initial monomer concentration effect, which only becomes slightly apparent at concentrations smaller than $1 \%$. Final conversion and reaction rates as a function of temperature, type and initiator concentration change as observed in other systems. Final particle sizes are between 20 and $60 \mathrm{~nm}$, and final molar masses are of the order of $106 \mathrm{~g} / \mathrm{mol}$.

\section{Acknowledgements}

Financial support for this work from Ministerio de Ciencia y Tecnología is gratefully acknowledged. Dr. Jesús Arellano acknowledges the award of a fellowship from the ICI (Instituto de Cooperación Iberoamericana).

\section{REFERENCES}

[1] A. Kumar and R. K. Gupta, Eds., "Fundamentals of Polymer Engineering," Marcel Dekker, New York, 2003.

[2] F. Candau, "Encyclopedia of Polymer Science and Engineering," Wiley, New York, 1989.

[3] J. O. Stoffer and T. Bone, J. Dispersion Sci. Technol., Vol. 18, 1980, pp. 2641.

[4] Stoffer, J. O. and Bone, T., J. Sci. Polym. Chem., 1980, $18,2641$.

[5] Pérez Luna V. H., M. S. Thesis, Universidad de Guadalajara, México, 1989.

[6] Pérez Luna V. H., Puig, E., Grun, L. U., Kaler, E. W., Minter, J.R., Mourey,T.H. and Texter, J., Macromolecules, 25 (1992) 5157.

[7] Fanun M. (Editor) "Microemulsions. Properties and Applications," CRC Press, Boca Raton 2009.

[8] Full, A. P., Puig, E, Grun, L. U., Kaler, E. W., Minter, J.R., Mourey,T.H. and Texter 1., Macromolecules, 25 (1992) 5157.

[9] Puig, E., Pérez-Luna, V. H, Pérez-González, M., Macías, E. R., Rodríguez, B.E. and Kaler, E. W., Colloid Polym. Sci., 271 (1993) 114. 
[10] Rodríguez-Guadarrama, L. A., Mendizábal, E., Puig, E. and Kaler, E. W., J. Appl. Polym. Sci., 48 (1993) 775.

[11] Rodríguez-Guadarrama, L.A., M.S. Thesis. Universidad de Guadalajara. México, 1992.

[12] Gan, L. M., Chew, C. H., Lee, K. C. and Ng, S. C., Polymer, 34 (1993) 3064.

[13] Gan, L. M., Chew, C. H., Lee, K. C. and Ng, S. C., Polymer, 35 (1994) 2659.

[14] Escalante-Vázquez., J. I, Rodríguez-Guadarrama, L. A., Mendizábal, E., Puig, J, López, R. G. and Katime, I., J. Appl. Polym. Sci., 62 (1996)1313.

[15] López, R. G., Treviño, M. E. Salazár, L. V. Peralta, R. P, Becerra; F., Puig, J. E. and Mendizábal, E., Polym. Bull., 38 (1997) 411.

[16] Inchausti, I., Sasia, P. M. and Katime, I., J. Mater. Sci., 40 (2005) 1.

[17] Chow, P. Y. and Gan L. M., Adv. Polym. Sci., 175 (2005) 257.

[18] Sosa, N., Peralta, R. D., López, R. G., Ramos, L. F., Katime, I., Cesteros, C., Mendizábal, E. and Puig, J., Polymer, 42 (2001) 6923.

[19] Guo, J. S., Sudol, E. D., Vanderhoff, J. W. and El-Aasser, M. S. M. S., J. Polym. Sci. Polym. Chem. Ed., 30 (1992) 691.

[20] Puig, J, Mendizábal, E., Delgado, S., Arellano, J. and López-Serrano, F., C.R. Chimie, 6, (2003) 1267.

[21] Delgado, S., M. S. Thesis. Universidad de Guadalajara. México, 1994.

[22] Arellano, J., M. S. Thesis. Universidad de Guadalajara. México, 1994.

[23] Full, A. P., Kaler, E. W., Arellano, J. and Puig, J., Macromolecules, 29 (1996) 2764.

[24] Renteria, M., Muñoz, M., Ochoa, J. R., Cesteros, L.C. and Katime, I., J. Polym. Sci. Part A, Polym. Chem., 43 (2005) 2495.

[25] Abu-Reziq, R., Blum, J. and Avnir, D., Chem. A Eur. J., 10 (2004) 958.

[26] Katime I., Arellano J., Mendizábal E. and Puig J. "Synthesis and characterization of poly(n-hexyl methacrylate) in three-component microemulsion", Eur. Polym. J., 37(11), 2273-2279 (2001).

[27] Mendizábal E., Puig J., López-Cuenca S., Rabelero M. and Katime I. "Latexes of core-shell polymers with high solid content prepared by microemulsion polymerization," Ann. Techn. Conf., 60(3), 3864-3867 (2002).

[28] Capek I. and Potisk, P., Macromol. Chem. Phys., 196 (1995) 723.

[29] Capek I. and Potisk, P., Die Angewndte Makromoleculare, 222 (1994) 125.

[30] Capek I., Juranucova, V., Barton, J. and Ito, K., Polymer Intern., 43 (1997) 1.

[31] Katime I., Katime O. and Katime D. "Introducción a la ciencia de los materiales polímeros: Síntesis y caracterización”. Servicio Editorial Bilbao, 2010.

[32] Mark, H. F., Bikales, N. M., Overberger, Ch. G. and Manges, G. "Encyclopedia of Polymer Science and Engeneering". (2a edition) John Wiley \& Sons. Vol. 1, 1985.

[33] Katime, I., Arellano, J. and Schulz, P., J. Colloid \& Interf. Sci., 296 (2006) 490.

[34] WAKO Pure Chemical Industries, Ltd., Japan 1987. Azo Polymerization Initiator Technical Brochure.

[35] Brandrup, I. and Immergut, E. H. (Editors) "Polymer Handbook," 4th edition, Wiley, New York, 2003.

[36] Lovell P. A. and El-Aasser (Editors) "Emulsion Polyerization and Emulsion Polymers," Wiley, New York. 1997. 